\title{
Classe hospitalar e 0 direito à educação da criança hospitalizada
}

\author{
Hospital class and the right to education of the hospitalized child
}

\author{
Brunella Poltronieri Miguez ${ }^{1}$ \\ Silvia Moreira Trugilho ${ }^{2}$ \\ Hiran Pinel ${ }^{3}$
}

Solange Rodrigues da Costa Nascimento ${ }^{4}$

\section{RESUMO}

Crianças e adolescentes em condição de adoecimento vivenciam obstáculos que interferem em sua escolarização, haja vista os frequentes e/ou prolongados processos de tratamento e de hospitalização a que se submetem. Nesse contexto, as classes hospitalares configuram-se uma estratégia para favorecer a manutenção da educação para esse grupo. Assim, o artigo busca realizar uma reflexão sobre o direito à educação da criança em condição de enfermidade e de hospitalização, tomando como cenário a realidade do processo educacional desenvolvido na classe hospitalar de um hospital público estadual

\footnotetext{
${ }^{1}$ Advogada. Mestre em Políticas Públicas e Desenvolvimento Social Local pela Escola Superior de Ciências da Santa Casa de Misericórdia de Vitória (EMESCAM). Pós-graduada em Direito Público pela Faculdade de Direito de Vitória (FDV). Assessora jurídica e revisora do Núcleo de Estudos da Consultoria Legislativa do Senado Federal. Telefone 5527 99993-8455. E-mail: advbrunellamiguez@gmail.com.

${ }^{2}$ Assistente social. Doutora em Educação pela Universidade Federal do Espírito Santo. Docente do Programa de Políticas Públicas e Desenvolvimento Local da Escola Superior de Ciências da Santa Casa de Misericórdia de Vitória - EMESCAM. E-mail: silvia.trugilho@emescam.br

${ }^{3}$ Psicólogo e pedagogo. Pós-doutorado em Educação, Universidade Federal de Minas Gerais, UFMG. Doutor em Psicologia, Universidade de São Paulo, USP. Mestre em Educação, Universidade Federal do Espírito Santo, UFES. Especialista em Saúde Pública. Professor titular aposentado do DETEPE/UFES/CE. Coordenador do Grupo de Fenomenologia, Educação (Especial) e Inclusão (GRUFEI). E-mail: hiranpinel@ gmail.com

${ }^{4}$ Enfermeira. Doutora em Educação pela Universidade Federal do Espírito Santo. Docente do Programa de Políticas Públicas e Desenvolvimento Local da Escola Superior de Ciências da Santa Casa de Misericórdia de Vitória - EMESCAM e das graduações de Enfermagem e Medicina. Vitória, ES, E-mail: solange.costa@emescam.br.
}

\begin{tabular}{|l|l|l|l|l|l|}
\hline Serv. Soc. \& Saúde & Campinas, SP & v. 19 & $1-25$ & e020002 & e-ISSN 2446-5992
\end{tabular}




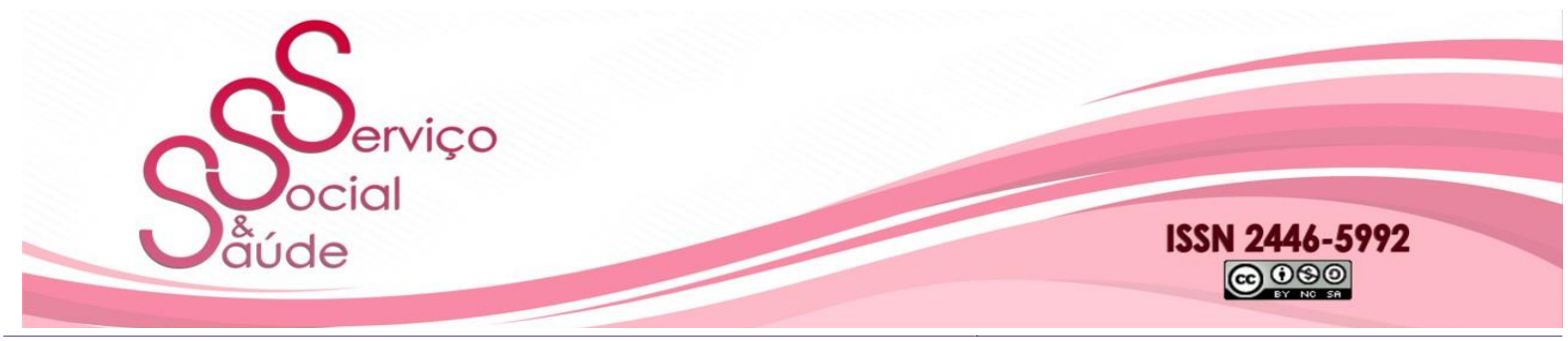

doi: $10.20396 /$ sss.v19i0.8661055

situado na região metropolitana da Grande Vitória, no estado do Espírito Santo, na correlação com a legislação que apregoa a manutenção da educação para crianças e adolescentes hospitalizados. O texto resulta de um estudo de caso qualitativo, realizado a partir de observação direta e de realização de entrevistas com os profissionais da classe hospitalar investigada. Os dados obtidos foram tratados pelo método de análise de conteúdo. Aponta-se que, apesar da prática educativa das classes hospitalares ser formalmente reconhecida pela legislação no campo da educação, sua realização esbarra em condições objetivas de estrutura, recursos e de articulação com as escolas. Foi possível extrair que embora o acesso à educação seja viabilizado na classe hospitalar, o direito à educação escolarizada não necessariamente resta assegurado, pois a própria gestão pública deixa de cumprir com suas competências para a viabilização da classe hospitalar como política educacional.

PALAVRAS-CHAVE: Classe hospitalar. Direito à educação. Criança hospitalizada. Sujeitos de direito.

\begin{abstract}
Children and adolescents in a condition of illness experience obstacles that interfere with their schooling, given the frequent and/or prolonged processes of treatment and hospitalization which they undergo. In this setting, hospital classes are configured as a strategy to favor the maintenance of education for this group. Thus, the article aims to reflect on the right to education of children in conditions of illness and hospitalization, taking as a scenario the reality of the educational process developed in the hospital class of a state public hospital located in the Greater Vitória Metropolitan Area, in the state do Espirito Santo, Brazil, in its correlation with the legislation that proclaims the maintenance of education for hospitalized children and adolescents. The text is the result of a qualitative case study, carried out through direct observation and interviews with professionals from the investigated hospital class. The data obtained were treated using the content analysis method. The study concludes that even though the educational practice of hospital classes is formally recognized by the legislation in the field of education, its realization goes against objective conditions of structure, resources and interconnection with schools. We could understand that even though access to education is made possible in the hospital class, the right to schooled education is not necessarily guaranteed, as the public administration itself fails to comply with its duty to make the hospital class feasible as an educational policy.
\end{abstract}

KEYWORDS: Hospital Class. Right to Education. Hospitalized Child. Subjects of Law.

\title{
INTRODUÇÃO
}

A educação firmada como direito é uma via para a criação de condições de acesso do cidadão às esferas da vida social. Para além da perspectiva instrumental, a educação deve ser vislumbrada como um importante elemento nas relações do cidadão tanto com a sua própria realidade, quanto das suas relações com a realidade que o cerca. 


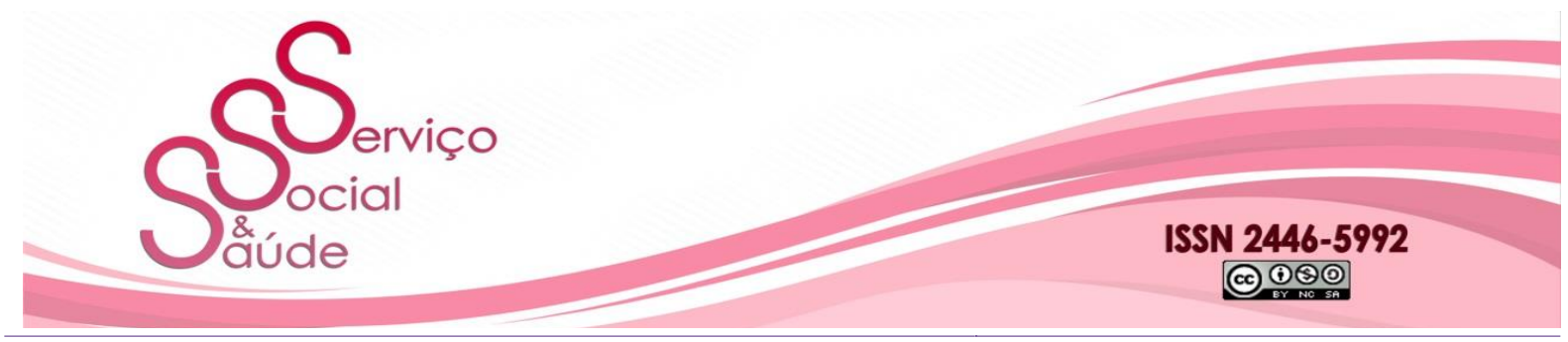

doi: $10.20396 /$ sss.v19i0.8661055

3

A concepção de direito à educação para todos, sem distinção de qualquer natureza, passou a ser positivada a partir de 1948, com a formalização da Declaração Universal dos Direitos Humanos, mais precisamente no artigo 26 do referido documento. O mencionado texto das Nações Unidas apregoa que "todo ser humano tem direito à instrução" e que a “instrução será gratuita pelo menos nos graus elementares e fundamentais” (ONU, 2009).

Em 1988, a Constituição da República, em um título específico, denominado "Dos Direitos e Garantias Fundamentais", elevou a Educação como direito fundamental de caráter social. Ao dispor sobre o direito à educação, sobretudo quanto ao seu acesso universal, conforme é possível verificar a partir do caput do artigo $6^{\circ}$, a Constituição da República em muito avançou, comparando-se com as cartas constitucionais que a precederam, já que pela primeira vez tal garantia alcançou o patamar de direito fundamental.

Ainda, em uma análise sistemática, depreende-se que a Constituição da República de 1988 lançou as bases para a concepção de uma doutrina de proteção integral da criança e do adolescente, consoante se pode extrair, sobretudo, do artigo 227 que disciplina que é dever da família, da sociedade e do Estado assegurar com absoluta prioridade o direito à vida, à saúde, à educação, à alimentação, ao lazer, à profissionalização, à cultura e à dignidade desses sujeitos.

Consolidando as diretrizes da Constituição da República de 1988, o Estatuto da Criança e do Adolescente (Lei $n^{\circ}$ 8.069/90) respaldou a doutrina de proteção integral da criança e do adolescente, levando em conta a condição de sujeitos em desenvolvimento, bem como dispôs sobre o direito à educação e o direito à saúde em relação a esse grupo específico. Há outros diplomas legais que também refletem preocupação particular com os direitos relacionados à educação da criança e do adolescente, como a Lei de Diretrizes e Bases da Educação Nacional (Lei nº 9.394/96).

Extrai-se, diante desses apontamentos preliminares, a importância do direito à educação - diga-se de passagem - indispensável ao desenvolvimento humano e, sobretudo, infere-se o reconhecimento de tal essencialidade pela legislação, de modo que cabe ao Estado \begin{tabular}{|l|l|l|l|l|l|}
\hline Serv. Soc. \& Saúde & Campinas, SP & v. 19 & $1-25$ & e020002 & e-ISSN 2446-5992
\end{tabular} 


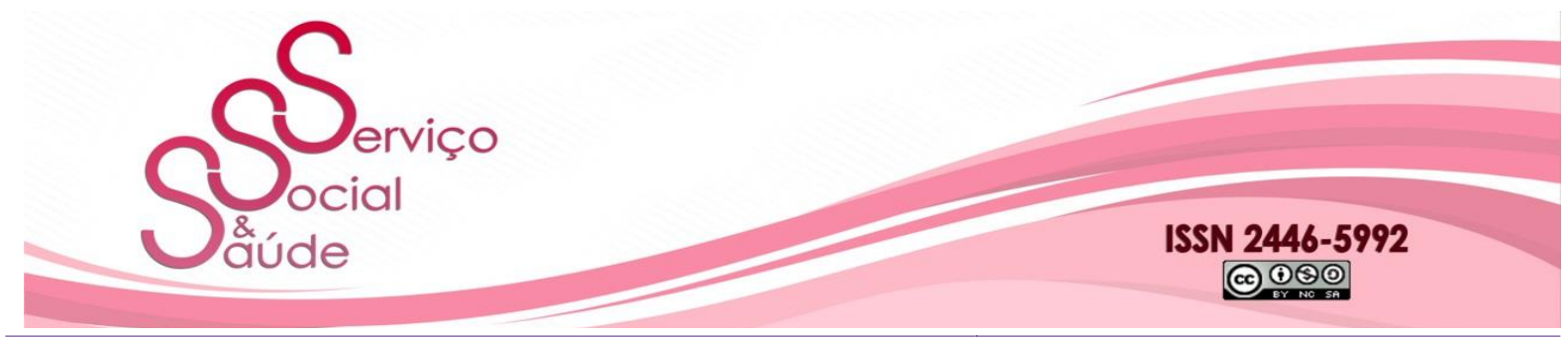

doi: $10.20396 /$ sss.v19i0.8661055

promover mecanismos, estratégias e espaço-tempo diferenciados que possam atender às especificidades dos destinatários da educação, objetivando nesse sentido, a universalização do atendimento escolar.

Segundo Freire (2011), a prática educativa, enquanto prática política e cultural, deve estar endereçada aos seres humanos e, por isso, se estende aos mais diversos espaços sociais. Na mesma linha de pensamento, Brandão (1981, p. 7) afirma que "Ninguém escapa da educação. Em casa, na rua, na igreja ou na escola, de um modo ou de muitos, todos nós envolvemos pedaços da vida com ela [...]".

No esforço de significar a finalidade da educação na vida do ser humano, Saviani (2003) defende a educação enquanto mediadora para a construção do indivíduo como ser social. Ainda para o autor, a educação é tida como uma ação que produz humanidade no indivíduo e essa perspectiva toca inúmeras outras dimensões de sua vida social, como o conhecimento e o estabelecimento de valores, atitudes, ideias que o possibilitam apreender o mundo e, nesse sentido, humanizar-se. Para Freire (2011), a educação é determinante para a relação do indivíduo com o mundo ao seu redor.

Partindo da percepção de relevância da educação no desenvolvimento cidadão do indivíduo e da perspectiva de que a educação pode acontecer extramuros ao espaço escolar tradicional, já que se trata de um processo constante na vida dos sujeitos, tem-se o cenário que constitui o pano de fundo e que respalda o atendimento educacional em classes hospitalares, como um aliado na continuação do processo educativo daquelas crianças ou adolescentes que, por condições de saúde, restam impossibilitados de frequentar os ambientes escolares formais.

A insustentável permanência do aluno na escola regular, como é o caso da criança e do adolescente que se encontram adoecidos ou na condição de hospitalizados, invoca a necessidade de se repensar as práticas educativas, uma vez que o processo de internação hospitalar não pode de forma alguma cerceá-los do direito à educação, previsto em lei. Dessa forma, as classes hospitalares podem representar uma política pública estratégica para a conciliação do acesso à saúde e à educação concomitantemente. 


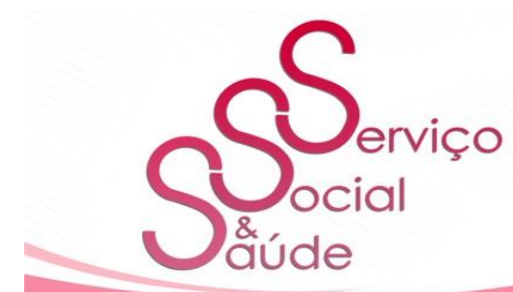

ISSN 2446-5992

(c) (i) (3) (2)

doi: $10.20396 /$ sss.v19i0.8661055

Parte-se da consideração de que a classe hospitalar se põe como uma importante estratégia para a continuidade do desenvolvimento estudantil de crianças e adolescentes durante o período de hospitalização. Nesse mesmo sentido, ao passo que cumpre com o compromisso educacional, a classe deve estar empenhada na tarefa de suavização dos impactos decorrentes da internação e do afastamento físico e emocional do aluno adoecido da escola, levando em consideração, claro, o complexo cenário circunscrito pela situação de enfermidade.

Assim, o texto objetiva apresentar uma reflexão sobre o direito à educação da criança em condição de enfermidade e de hospitalização, tomando como cenário a realidade do processo educacional desenvolvido na classe hospitalar de um hospital público estadual situado na região metropolitana da Grande Vitória, no estado do Espírito Santo, na correlação com a legislação que apregoa a manutenção da educação para crianças e adolescentes hospitalizados.

\section{PROCEDIMENTOS METODOLÓGICOS}

O presente texto resulta de uma pesquisa de abordagem qualitativa e, tendo em vista a amplitude e o entrelaçamento de diversos fatores na ocorrência do fenômeno social em estudo, a abordagem qualitativa se serviu do expediente do estudo de caso, recurso que atende à necessidade da investigação em profundidade. A utilização do estudo de caso como estratégia desta pesquisa mostrou-se fundamental para reflexão sobre o atendimento educacional na classe hospitalar investigada, possibilitando o contato com as fontes de informação, tais como os atores sociais, essenciais à coleta de dados.

A escolha do local de realização do estudo foi precedida por um estudo preliminar dos hospitais de internação pediátrica da Região Metropolitana da Grande Vitória. A estratégia adotada foi a realização de um levantamento, seguido da catalogação de todos os hospitais de internação, públicos e privados da região citada com os respectivos contatos telefônicos. $\mathrm{Na}$ 


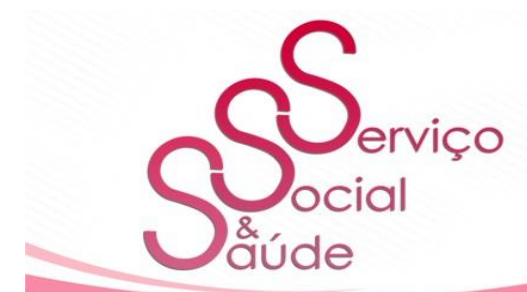

ISSN 2446-5992

(c) (i) (3) (2)

doi: $10.20396 /$ sss.v19i0.8661055

sequência foram realizadas ligações para cada unidade catalogada, em busca de verificar quais delas possuíam alas de internação pediátrica e, caso positivo, se contavam com os recursos de classes hospitalares e/ou brinquedotecas.

Foi constatado que, dos hospitais que possuem ala de internação pediátrica, somente 02 (dois) possuem o recurso da classe hospitalar, sendo importante ressaltar que ambos são públicos. A decisão entre as duas classes hospitalares existentes se deu considerando aquela que apresentava o maior tempo de funcionamento. Escolheu-se a que se encontra em funcionamento desde 2000, e oficializada em convênio com a Secretaria de Estado da Educação (SEDU) em 2003.

O tempo de funcionamento da classe hospitalar foi considerado um indicativo de estabilidade da atividade investigada pelo tempo de experiência no atendimento a crianças e adolescentes em situação de adoecimento e hospitalização. Além disso, o fato de o hospital onde está instalada a classe constituir-se em hospital de referência para o atendimento de urgência/emergência e de especialidades pediátricas de alta complexidade influenciou o processo de escolha.

A obtenção de dados se deu por meio de observação direta e realização de entrevistas semiestruturadas realizadas com os profissionais que atuam na classe hospitalar investigada (uma coordenadora e nove professores). Os dados obtidos foram tratados pelo método de análise de conteúdo, sistematizado por Bardin (1977). A pesquisa encontra-se registrada na Plataforma Brasil sob o número 20161419.5.0000.5065 do Certificado de Apresentação para Apreciação Ética (CAAE), tendo sido aprovada por Comitê de Ética em Pesquisa. 


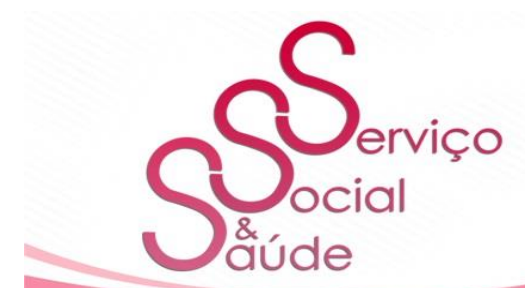

\section{ATENDIMENTO EDUCACIONAL HOSPITALAR: INTERFACE ENTRE EDUCAÇÃO E SAÚDE}

A perspectiva de atendimento educacional para crianças e adolescentes hospitalizados se institucionaliza a partir de processos articulados entre o direito à Saúde, o direito à Educação, os direitos inerentes à criança e ao adolescente e os movimentos sociais que contribuíram e contribuem para a efetivação de políticas públicas que materializam a oferta de serviços de saúde e educação, com base nos princípios da inclusão e da integralidade, respectivamente.

A hospitalização é uma realidade dolorosa e inevitável para parte significativa da população. Para Fonseca (2008), o hospital é um lugar impessoal, porque qualquer pessoa pode ser hospitalizada e isto, consequentemente, enseja a perda da identidade e do papel social que aquele sujeito até então desenvolvia, passando a ser reconhecido meramente por um número de leito ou pela enfermidade que possui.

E essa realidade torna-se ainda mais hostil e complexa quando figuram como parte crianças e adolescentes, considerados sujeitos em desenvolvimento - característica peculiar que os diferencia dos adultos. Tal processo de desenvolvimento se manifesta, de forma conjugada, no amadurecimento corporal, sexual, cerebral, psicológico, profissional, provocando comportamentos e reações antes não sentidas pelo adolescente ou não observadas por conviventes próximos.

Considerando o processo de despersonificação pelo qual passa a criança hospitalizada, acrescentam Zardo e Freitas (2007) que o estigma de doente e a condição de passividade da criança hospitalizada influenciam no processo de construção de valores (intra e interpessoais), bem como na formação de conceitos de homem e mundo.

Nessa mesma linha, corrobora Torres (1999, p. 148) ao afirmar que diante de uma doença que debilita o físico, restringe as perspectivas de futuro, que compromete o lado 


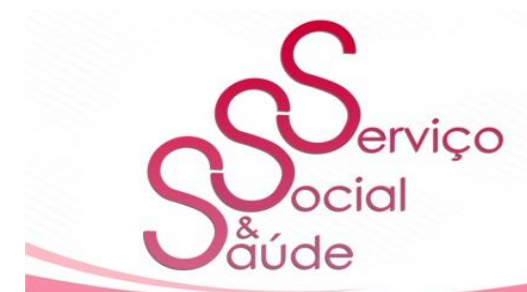

ISSN 2446-5992

(c) (i) (3) (2)

doi: $10.20396 /$ sss.v19i0.8661055

emocional e o social, as crianças e os adolescentes se tornam seres cassados em seus anseios e urgências, o que lhes confere uma espécie de "cidadania às avessas", ou seja, a "cidadania dos direitos negados".

Por tal razão, a situação de opressão experimentada pela criança hospitalizada deve ser motivo de reflexão, sobretudo, por parte do Estado que reconhece sua condição de sujeito de direitos. Daí porque o processo de hospitalização deve possibilitar o ponto de encontro entre saúde e educação, para garantir além da saúde e da integridade física da criança e do adolescente, os processos cognitivos, afetivos, o bem-estar, além da continuidade do processo de aprendizado.

O hospital deve constituir ambiente propício ao desenvolvimento integral da criança, de modo que condições temporárias não figurem como limitadoras ao processo de aprendizagem da criança e do adolescente em condições de adoecimento, propiciando, ao longo do tratamento hospitalar, a efetivação dos direitos à educação e à saúde concomitantemente.

Essa simbiose pode ser explicada por Fonseca (1999) que afirma que, se a escola deve ser promotora da saúde, o hospital pode ser mantenedor da escolarização. O mesmo entendimento comunga Alves (2001) ao afirmar que se ensina e se aprende em todos os tempos e espaços.

A partir da construção teórica de Vygostky (2001), no sentido de que o desenvolvimento não decorre de um processo interno da criança, mas sim por meio de sua interação social, a aprendizagem conquista importante espaço no processo de desenvolvimento humano. É nesse processo dinâmico que ela acontece e não pode ser objeto de interrupção.

Nesse panorama, a classe hospitalar constitui importante ferramenta, capaz de propiciar a recuperação e a socialização da criança hospitalizada através de um processo inclusivo, promovendo a continuidade da aprendizagem, devolvendo àquela o que lhe foi 


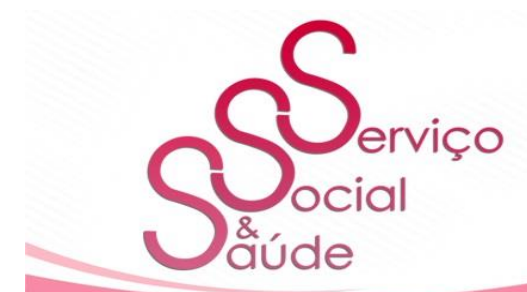

ISSN 2446-5992

(c) (i) (3) (2)

doi: $10.20396 /$ sss.v19i0.8661055

suprimido em razão da internação ou do período de tratamento, contribuindo de maneira significativa para a recuperação física e mental do infante.

No escólio de Ortiz e Freitas (2005, p. 24) tal modalidade de ensino constitui-se como “espaço do aprender em situação hospitalar”, caracterizando uma ação educacional que existe simultaneamente ao entorno problematizador, a fim de que a criança e o adolescente não sejam absorvidos em outra situação de conflito, quer seja, durante o tratamento, quer seja, após o término, afastando o despreparo para a vida escolar. Para as autoras, as crianças hospitalizadas inserem-se no perfil de alunos temporários da educação especial e, por esse motivo, devem ter uma assistência preventiva contra o fracasso escolar, reprovação e evasão.

Dessa forma, o atendimento pedagógico-educacional nas instituições hospitalares, materializado pelas denominadas classes hospitalares, representa a inter-relação das áreas da saúde e educação como forma de promoção do desenvolvimento integral e do tratamento humanizado de crianças e adolescentes em condição de hospitalização.

Estar hospitalizado não significa exclusão e a classe hospitalar possibilita esse processo aprender-crescer-desenvolver-se, ainda que fora dos muros da escola tradicional. Colaborando com tal percepção, Zombini et al. (2012, p. 80) afirmam que

[...] a construção da prática pedagógica para atuação em ambiente hospitalar deve, assim, transpor as barreiras da educação tradicional e da visão compartimentada e reducionista, promovendo o aperfeiçoamento humano como um todo, contribuindo assim para o desenvolvimento infantil e ampliando sua experiência de vida (2012, p. 80).

É sob esse olhar abrangente que se realça a importância da educação no hospital, como forma de resgatar a continuidade da vida. Para Fonseca (2008), a escola hospitalar traz um conceito amplo de cidadania, porque antes de qualquer coisa, a criança é um cidadão, como qualquer outro, tem direito ao atendimento de suas necessidades e interesses, mesmo nas situações de saúde comprometida. Ser cidadão, dentre as várias dimensões da cidadania, compreende "[...] o reconhecimento do indivíduo como pessoa integrada na sociedade [...]" (SILVA, 2009, p. 154).

\begin{tabular}{l|l|l|l|l|l}
\hline Serv. Soc. \& Saúde & Campinas, SP & v. 19 & $1-25$ & e020002 & e-ISSN 2446-5992 \\
\hline
\end{tabular}




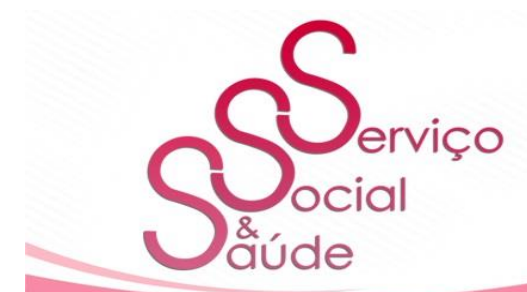

ISSN 2446-5992

(c) (i) (3) (2)

doi: $10.20396 /$ sss.v19i0.8661055

A bem da verdade, a criança hospitalizada quando percebe que pode produzir e aprender, ganha vida. Nas palavras de Fontes (2005, p. 24) “[...] a aprendizagem no hospital é vida [...]", ou seja, diferente do aprendizado formal limitado aos aspectos cognitivos do saber, o aprender no hospital alcança outro sentido, representa sinal de saúde, significa a vida pulsando, simboliza o retorno ao referencial da infância que é a escola.

Dessa forma, as intervenções educativas no contexto hospitalar visam tornar a experiência de hospitalização como um fato positivo, uma vez que não se resumem ao processo de transmissão de conteúdo formal, ligado à base curricular, propiciam também implicações significativas nas particularidades do processo saúde-doença, amenizando a sensação de adoecimento e de insegurança geradas pelo tratamento hospitalar e até mesmo o sentimento de perda temporária da vida.

\section{A LEGISLAÇÃo E O DIREITO À EDUCAÇÃo DA CRIANÇA E DO ADOLESCENTE HOSPITALIZADO}

O artigo 208, caput e inciso I da CRFB/88 estabelecem que a Educação é dever do Estado, devendo ser efetivada de forma gratuita, assegurada a educação básica aos sujeitos de 4 (quatro) aos 17 (dezessete) anos, bem como àqueles que não tiveram acesso à Educação Básica em idade própria.

Dessa forma, em que pese não tratar especificamente do atendimento educacional hospitalar, a Constituição Federal projetou um caminho de acesso mais igualitário e humanizado para aqueles que apresentam necessidades educacionais especiais, ainda que temporárias - aqui se incluem aqueles que por questões de saúde encontram-se impossibilitados de frequentar a escola de forma regular.

Frente ao que dispunha a Constituição Federal, diversos instrumentos legais foram produzidos como forma de regulamentar os direitos ali consagrados. Fundamentado na 


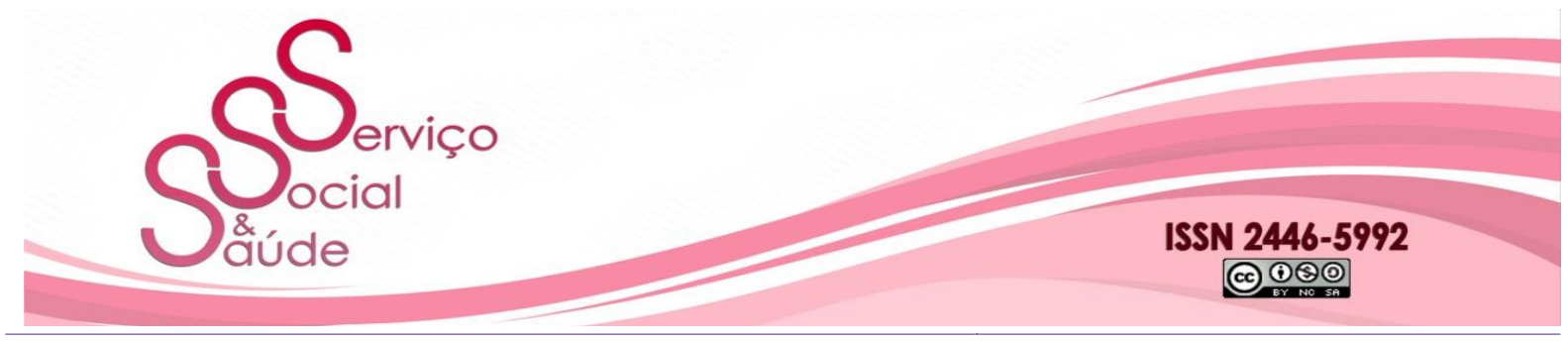

doi: $10.20396 /$ sss.v19i0.8661055

concepção de que crianças e adolescentes são sujeitos de direito, o Estatuto da Criança e do Adolescente (Lei no 8.069, de 13 de julho de 1990) constituiu um dos documentos marco que promoveu mudanças substanciais em relação ao tratamento da criança e do adolescente e, no que diz respeito à garantia de acesso à educação, assegurou a igualdade de condições para o acesso e permanência na escola (artigo 53, inciso I), reforçando a normativa da Constituição Federal.

Legitimando os direitos das crianças e dos adolescentes hospitalizados, a Lei ${ }^{\circ}$ 9.394, de 20 de dezembro de 1996, conhecida como Lei de Diretrizes e Bases da Educação Nacional (LDB) assevera que, para garantir a obrigatoriedade do ensino, o Poder Público, criará formas alternativas de acesso aos diferentes níveis de ensino (artigo $5^{\circ}, \S 5^{\circ}$ ), podendo organizar-se de diferentes formas para garantir o processo de aprendizagem (artigo 23). Afirma, ainda, que para os educandos com necessidades educacionais especiais, os sistemas de ensino assegurarão currículos, métodos, técnicas, recursos educativos e organização específicos para atendê-los (artigo 59).

Recentemente, no ano de 2018, a Lei 13.716, de 24 de setembro de 2018, alterou a LDB para assegurar, especificamente, o atendimento educacional ao aluno da educação básica internado para tratamento de saúde em regime hospitalar ou domiciliar por tempo prolongado $\left(\operatorname{artigo} 4^{\circ}-\mathrm{A}\right)$.

Regulamentando as práticas educativas em ambiente hospitalar, o Conselho Nacional dos Direitos da Criança e do Adolescente (CONANDA) editou a Resolução no 41, de 13 de outubro de 1995, que privilegia os direitos inerentes à criança e ao adolescente hospitalizados, dentre os quais é possível citar "o direito de desfrutar de alguma forma de recreação, programas de educação para a saúde, acompanhamento do currículo escolar durante sua permanência hospitalar” (BRASIL, 1995).

Mais adiante, em 2001, a Câmara de Educação Básica do Conselho Nacional da Educação, por meio da Resolução $n^{\circ}$ 2, de 11 de setembro de 2001, instituiu as Diretrizes Nacionais para a Educação Especial na Educação Básica, que também dedicou parte de sua 


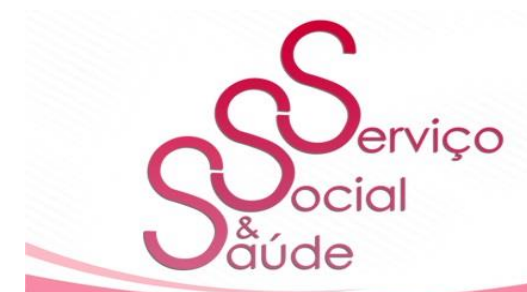

ISSN 2446-5992

(c) (i) (3) (2)

doi: $10.20396 /$ sss.v19i0.8661055

proposição para o atendimento pedagógico para crianças adoentadas e impedidas de frequentar a escola regular. Nesse sentido, contemplou a ação integrada entre os Sistemas de Saúde e Educação para a organização do atendimento educacional especializado aos alunos impossibilitados de frequentar as aulas em razão de tratamento de saúde, quer seja, em decorrência de internação, quer seja, via atendimento ambulatorial ou permanência prolongada em domicílio.

No ano de 2002, o Ministério da Educação (MEC) elaborou um documento intitulado "Classe hospitalar e atendimento pedagógico domiciliar: estratégias e orientações", que conferiu maior visibilidade a essa modalidade de atendimento educacional especial. Esse documento, apesar de não ter caráter legislativo, possui cunho orientador, na medida em que estrutura ações de organização no âmbito das classes hospitalares e do atendimento pedagógico domiciliar.

Dentre as diretrizes para a atuação dos profissionais nesses atendimentos, exigiu-se para o professor "formação pedagógica preferencialmente em Educação Especial ou em cursos de Pedagogia ou Licenciaturas" (BRASIL, 2002, p. 22) e ainda, "noções de conhecimento sobre as doenças e condições psicossociais vivenciadas pelos educandos e as características delas decorrentes, sejam do ponto de vista clínico, sejam do ponto de vista afetivo" (BRASIL, 2002, p. 22).

É pertinente observar que o documento também discorreu sobre a capacidade de o professor trabalhar com a diversidade humana e as diferentes vivências culturais, devendo identificar as necessidades especiais dos educandos impossibilitados de frequentar a escola para definir e implementar estratégias de flexibilização e adaptação curriculares. Assim, o material abre espaço para reflexões no sentido de se pensar a criança hospitalizada, como uma criança em estado especial, ainda que temporário, que requer cuidados especiais na abordagem educacional.

Observa-se também que o referido documento prevê a figura do professor coordenador, que além da função de coordenar a proposta pedagógica, a dinâmica e o \begin{tabular}{|l|l|l|l|l|l|}
\hline Serv. Soc. \& Saúde & Campinas, SP & v. 19 & $1-25$ & e020002 & e-ISSN 2446-5992
\end{tabular} 


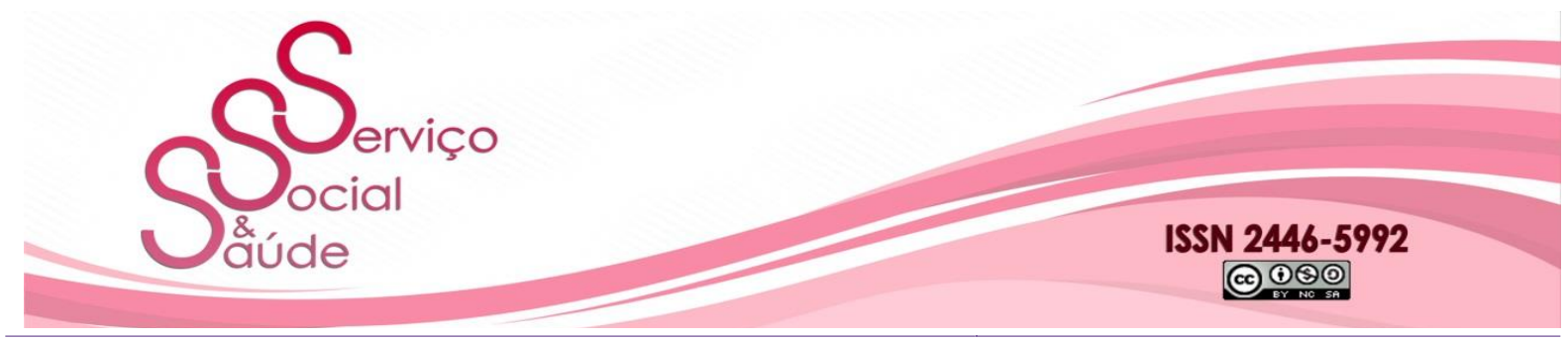

doi: $10.20396 /$ sss.v19i0.8661055

funcionamento da classe hospitalar, detém atribuição administrativa, devendo articular-se com a equipe de saúde do hospital, com a escola de origem do educando, assim como orientar os professores da classe hospitalar (BRASIL, 2002).

Existe, ainda, a previsão de um profissional de apoio ao professor, que pode pertencer ao quadro de pessoal do serviço de saúde ou do Sistema de Educação. Esses assistentes de apoio possuem, dentre outras, a função de "auxiliar o professor na organização do espaço e controle de frequência dos educandos; contribuir com a adequada higiene do ambiente e dos materiais" (BRASIL, 2002, p. 22).

Verifica-se que as mencionadas previsões legais legitimam a educação em âmbito hospitalar. Contudo, a modalidade de atendimento ainda se mostra tímida, considerando a integralidade do território nacional e o número de hospitais existentes no Brasil, sobretudo, desconhecida por grande parcela da sociedade. Prova disso é que no ano de 2015, havia apenas 155 classes registradas no Brasil, sem computar os atendimentos voluntários, cursos de extensão ou realizados por Organizações Não Governamentais (ONGs) (RAMOS, 2016).

Tendo em vista o cenário de que o direito à educação em contexto hospitalar fica restrito aos diplomas legais, faz-se necessário um olhar mais atento ao que está sendo efetivamente realizado de modo que possa favorecer a educação de crianças e adolescentes em condição de enfermidade e hospitalização.

\section{A EDUCAÇÃO DE CRIANÇAS E ADOLECENTES HOSPITALIZADOS ENTRE O}

\section{LEGAL E O REAL}

No âmbito da classe hospitalar pesquisada toda criança ou adolescente que frequenta o hospital, seja para realização de acompanhamento ambulatorial, seja em razão de internação, independente do agravo, é reconhecida como sujeito de direito ao atendimento pedagógico educacional ofertado a partir da classe hospitalar. Não há, assim, restrições ou delimitações impostas para acesso e usufruto do atendimento educacional realizado neste espaço destinado à educação. Para os profissionais que atuam nessa classe hospitalar, o direito à escolaridade 


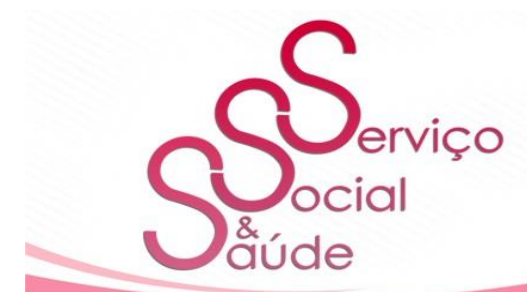

ISSN 2446-5992

(c) (i) (3) (2)

doi: $10.20396 /$ sss.v19i0.8661055

deve ser garantido independente de quaisquer condições e, com muito mais razão, às crianças e adolescentes que se encontram em situação de cuidados hospitalares.

A respeito do público-alvo atendido na classe hospitalar investigada, é possível afirmar que são crianças e adolescentes que necessitam de acompanhamento fora do espaço da escola regular e são considerados alunos temporários da Educação Especial. Segundo Gonçalves (2013), crianças e jovens hospitalizados não são considerados como público-alvo da Educação Especial pelo simples fato do adoecimento e hospitalização, no entanto, durante o período da internação podem apresentar condição temporária de alteração física, psíquica ou emocional para as quais deve ser promovida atenção especial e, sobretudo, acessibilidade, ainda que as limitações sejam temporárias.

Nessa linha de raciocínio, todos os escolares em atendimento ou internação hospitalar (quer sejam, ou não, considerados público-alvo da Educação Especial) constituem-se destinatários do atendimento educacional desenvolvido na classe hospitalar. Portanto, o atendimento educacional ofertado em classe hospitalar engloba aqueles que são considerados público-alvo da Educação Especial, assim como os que temporariamente dela se beneficiam.

Depreende-se que a dinâmica de trabalho da classe hospitalar é bem variada e exige a construção de uma estrutura e de prática pedagógica diferente da escola regular. A possibilidade de aulas nas enfermarias ou no espaço físico da própria classe hospitalar, o número variado de alunos, com enfermidades e características específicas, tais como, idade, fase escolar, condição socioeconômica e valores culturais, bem como com tempo de permanência diversificado, requer um trabalho docente flexível e adequado às necessidades dos alunos.

Neste aspecto, é importante atentar-se para os recursos didáticos necessários e utilizados para o desenvolvimento das atividades na classe hospitalar. Em relação a isso, os professores apontaram limitação de recursos disponíveis para a realização do processo educativo com os alunos da classe hospitalar, tendo que recorrer a diversas estratégias e, sobretudo, usar a criatividade.

\begin{tabular}{l|l|l|l|l|l}
\hline Serv. Soc. \& Saúde & Campinas, SP & v. 19 & $1-25$ & e020002 & e-ISSN 2446-5992
\end{tabular}




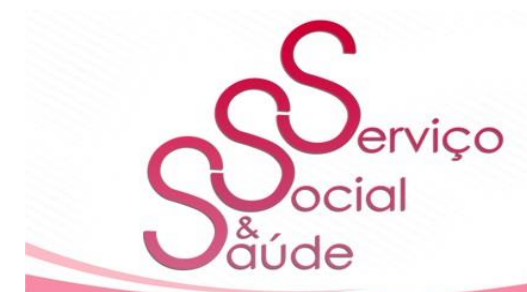

ISSN 2446-5992

(c) (i) (3) (2)

doi: $10.20396 /$ sss.v19i0.8661055

Em geral, na seara da educação não existe um só caminho ou estratégia de ensino a ser perseguido. Contudo, a igualdade deve nortear as ações educativas, ou seja, faz-se essencial que os alunos tenham as mesmas oportunidades, que podem ser oferecidas de forma diferenciada para cada um. Isso porque cada aluno aprende de uma forma específica e, por isso, cabe ao professor uma análise atenta das particularidades individuais do educando, para então eleger as ferramentas adequadas e, por conseguinte, estimular dois componentes básicos da aprendizagem: motivação e cognição.

Para que ocorra de fato o processo de aprendizagem, o aluno precisa entender, organizar, armazenar os conteúdos. Esses são processos cognitivos básicos que levam à construção do conhecimento. Segundo Freire (1996), a capacidade de aprender implica a nossa capacidade de apreender a substantividade do objeto apreendido, de modo que a memorização mecânica não representa o aprendizado verdadeiro.

Embora a função da classe hospitalar seja articular ações educativas para o regresso do aluno hospitalizado à escola comum, há a preocupação de um fazer pedagógico mais diferenciado, com estratégias e ações de cunho mais lúdico, que escapam dos moldes tradicionais de ensino e contribuem para auxiliar na cura da enfermidade e no retorno da criança e do adolescente à vida cotidiana. Sob esse prisma, é relevante consignar que embora a linha da classe hospitalar investigada seja a educativa-escolar, ou seja, que preconiza as exigências escolares formais, não se exclui a possibilidade de aliar a ludicidade, intencionalmente, ao ensino formal do conteúdo escolar.

Uma consideração merece ser feita e diz respeito à preparação e capacitação dos docentes para a atuação em espaços de atendimento educacional inseridos em hospitais. Todos os professores entrevistados relataram que não receberam por parte da Secretaria de Estado da Educação (SEDU) formação específica para o trabalho na classe hospitalar e que as iniciativas de atualização foram feitas às expensas, por vontade própria e que não há política de capacitação para o trabalho docente na classe hospitalar; ou seja, não há qualquer apoio institucional, nem mesmo colaboração para as iniciativas individuais de capacitação. 


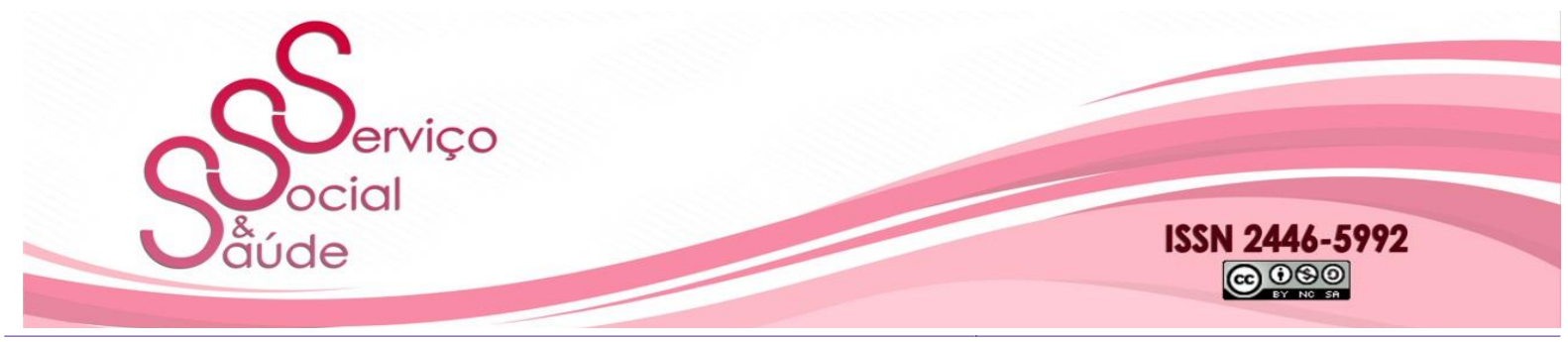

doi: $10.20396 /$ sss.v19i0.8661055

O interesse pela formação dos docentes que atuam na classe hospitalar encontra-se destacado no documento orientador intitulado "Classe hospitalar e o atendimento pedagógico domiciliar: estratégias e orientações", no sentido de que "os sistemas de ensino deverão criar oportunidades para formação continuada dos professores que atuam nas classes hospitalares [...]" (BRASIL, 2002, p. 25). O referido documento prevê ainda que "o professor deverá ter formação pedagógica preferencialmente em Educação Especial ou em cursos de Pedagogia ou licenciaturas [...]" (BRASIL, 2002, p. 22). Extrai-se, também, que "compete às Secretarias de Educação, atender à solicitação dos hospitais para o serviço de atendimento pedagógico hospitalar e domiciliar, a contratação e capacitação dos professores” (BRASIL, 2002, p. 15).

Barros (2007) observa que a falta de um treinamento para preparação dos professores que ingressam no contexto hospitalar - a fim de esclarecer sobre a rotina, a dinâmica de trabalho e os procedimentos técnicos - é um fator que concorre negativamente para o desempenho satisfatório dos docentes em tais contextos educacionais.

Para Assis (2009), a formação do professor atuante na classe hospitalar traz algumas características a serem destacadas, como estar aberto ao diálogo; dominar conhecimentos dos variados anos da Educação Básica; ter habilidade e competência para transitar entre os campos da saúde e da educação; firmar vínculos de afeto; ser mediador de conhecimentos e de relações interpessoais; conhecer e saber interpretar as necessidades educativas de seus alunos, agindo, quando necessário para modificar o currículo ou recorrer à tecnologia assistiva; ter maturidade emocional para lidar com o cotidiano hospitalar.

O perfil variado dos alunos da classe hospitalar, marcado pelas diferenças etárias, escolares e sociais, exige do professor um olhar diferenciado, que deve considerar também as necessidades educacionais especiais decorrentes de problemas de saúde, temporários ou permanentes. Entende-se, pois, que o escolar hospitalizado não é um escolar comum. Por esses motivos, cabe ao professor, ao buscar um planejamento de aprendizagem, se atentar às particularidades de cada aluno, realizando ajustamentos, adequações curriculares, conforme as necessidades do escolar, o que constitui uma prática educativa inclusiva. 


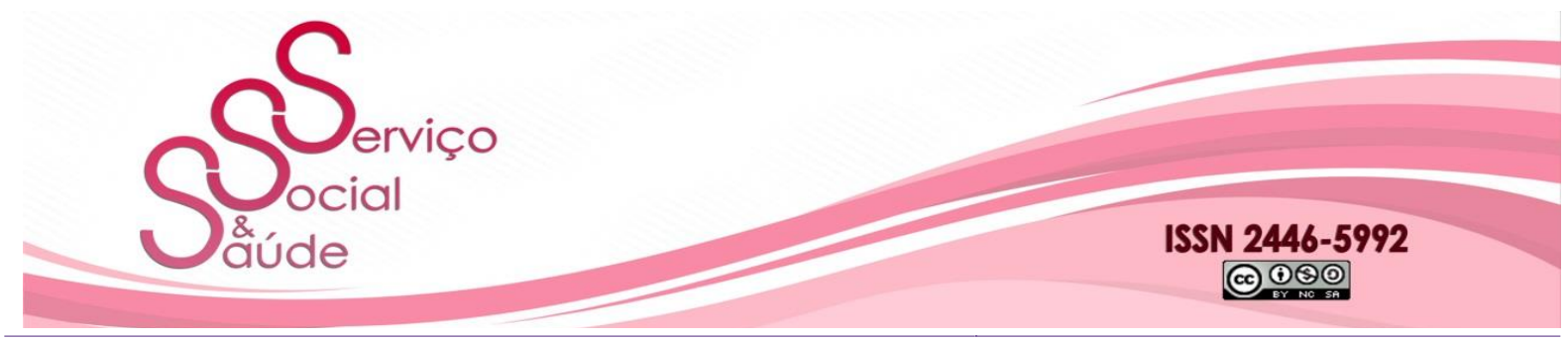

doi: $10.20396 /$ sss.v19i0.8661055

Como já assinalado anteriormente, o trabalho pedagógico desenvolvido na classe hospitalar segue a linha educativo-escolar como prática pedagógica. Nesse sentido, as práticas pedagógicas desenvolvidas na classe hospitalar estudada objetivam a continuidade do ensino dos conteúdos da escola de origem, a superação de lacunas deixadas pela escola regular e de eventuais dificuldades de aprendizagem em relação à escolaridade do aluno, assim como a aquisição de novos conteúdos pelo educando - o que requer uma boa articulação com a escola de origem do aluno.

No que se refere à relação estabelecida entre a classe hospitalar e a escola regular, os professores deixaram claro que há um fraco diálogo institucional e mesmo as tentativas individuais dos docentes esbarram em algumas dificuldades. Vale destacar que não se trata de falta de empenho ou de interesse por parte dos professores, resta evidenciado o problema das relações institucionais quanto ao cumprimento dos deveres estipulados para os estabelecimentos de ensino.

É nítido o interesse e o compromisso dos docentes em desenvolver com os educandos do Ensino Fundamental e Médio as atividades encaminhadas pela escola regular, inclusive as atividades avaliativas. Quando este envio não ocorre - situação que é rotineira na classe hospitalar investigada, conforme as narrativas obtidas - os professores elaboram as atividades por conta própria, com base nas referências curriculares do nível de ensino em que o aluno estiver matriculado.

O envolvimento dos professores com a escola de origem é essencial para o desenvolvimento do trabalho pedagógico educacional nas classes hospitalares, tendo em vista que tal ação se propõe a assegurar a manutenção dos vínculos escolares durante a hospitalização e facilitar o retorno do aluno para a rotina da escola regular, após a alta hospitalar. A falta de sinergia entre a classe hospitalar e a escola regular é um indicativo a ser levado em consideração quando o que se busca é a efetivação do direito à educação - que não se refere apenas ao acesso à escola, mas sim a condições reais de aprendizagem para todos os alunos. Legitimar o trabalho desenvolvido na classe hospitalar não significa enfraquecer o

\begin{tabular}{|l|l|l|l|l|l|}
\hline Serv. Soc. \& Saúde & Campinas, SP & v. 19 & $1-25$ & e020002 & e-ISSN 2446-5992
\end{tabular}




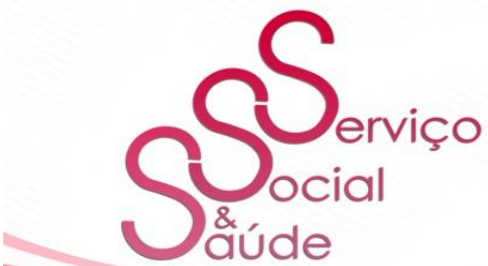

ISSN 2446-5992

(c) (i) (3) (2)

doi: $10.20396 /$ sss.v19i0.8661055

papel da escola.

Behrens (2012) registra que o êxito da educação do aluno hospitalizado está estreitamente relacionado ao planejamento entre o professor da classe hospitalar e o professor da escola de origem, de modo que o trabalho do professor da classe hospitalar, ainda que efetivo, pode futuramente gerar dificuldade para o aluno se integrar novamente no ensino regular, caso não seja realizada essa troca de informações com o estabelecimento de ensino.

Algumas dificuldades e desafios na efetivação do trabalho pedagógico educacional na classe hospitalar foram apontados pelos professores como prejudiciais à efetivação do direito à educação das crianças e dos adolescentes hospitalizados.

Apesar de estar de acordo com a previsão legal no que diz respeito à existência de espaço físico próprio e a possibilidade de ocorrência de aulas nas enfermarias, conforme determinação do MEC, constatou-se que a classe hospitalar investigada enfrenta problemas de limitação de espaço, de precariedade das instalações, bem como de carência de recursos financeiros, didáticos e tecnológicos. A falta de recursos financeiros e de material didático aponta a ausência de apoio por parte de gestores e dos órgãos públicos responsáveis no que tange à provisão de recursos indispensáveis ao funcionamento da classe hospitalar.

Impende ressaltar que a falta de material nas classes hospitalares não é um problema exclusivo e isolado da educação em âmbito hospitalar, mas sim de uma questão própria da Educação Básica no país, que também enfrenta percalços recorrentes no que diz respeito à infraestrutura física, às condições de trabalho dos professores, à política salarial do pessoal da educação e outros. Ou seja, o que se constatou na classe hospitalar representa apenas o micro retrato dos problemas estruturais do Sistema Educacional brasileiro.

Em documento orientador do Ministério da Educação (2002), que atribui estratégias para estruturação das classes hospitalares, existe a previsão de que compete às Secretarias de Educação a provisão de recursos financeiros e materiais para a realização do serviço de atendimento pedagógico hospitalar. Diante dessa orientação e do quadro de insuficiência 


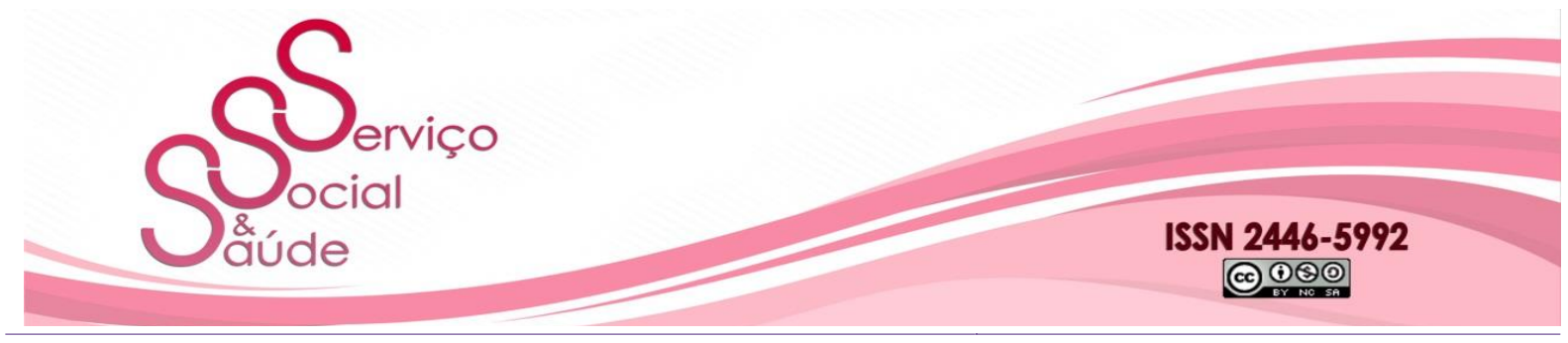

doi: $10.20396 /$ sss.v19i0.8661055

financeira que foi apurado, pode-se afirmar que existe um descompromisso por parte Secretaria Estadual de Educação para com a manutenção da classe hospitalar.

Outro elemento importante a ser destacado é a ausência de um Projeto Político Pedagógico (PPP) na classe hospitalar estudada, o que denota um problema tanto educacional como político. O PPP é o documento norteador da organização do trabalho pedagógico e sua importância vai além de um agrupamento de plano de atividades e de ensino, na medida em que representa uma ação intencional que direciona a escola democrática.

Para Veiga (2007), o projeto político-pedagógico, ao se constituir em processo democrático de decisões, visa instaurar uma forma de organização do trabalho pedagógico que busca superar conflitos, relações competitivas, corporativas e autoritárias, racionalizando a burocracia das relações no interior da escola.

No caso específico de uma classe hospitalar é necessário também considerar o artigo $58, \S 2^{\circ}$, da LDB e conjugá-lo com a Resolução 2 CNE/MEC/SEESP/01 que implementou a "hospitalização escolarizada", ou seja, o atendimento educacional em âmbito hospitalar por meio da assistência pedagógica prestada aos alunos com necessidades educacionais transitórias, bem como estabeleceu que devem constar nos projetos pedagógicos dos estabelecimentos de ensino diretrizes para $\mathrm{o}$ atendimento às necessidades educacionais especiais. Enfatiza-se, assim, a necessidade da construção de um PPP, a fim de que o trabalho pedagógico realizado na classe hospitalar não se torne uma prática assistencialista.

A dificuldade de articulação entre o trabalho educacional desenvolvido na classe hospitalar e nas escolas regulares, o fato dos professores serem contratados por designação temporária, resultando em queixas sobre a rotatividade de professores e a descontinuidade do trabalho desenvolvido, a falta de observância das diretrizes do MEC para a estruturação e funcionamento da classe hospitalar por parte dos órgãos gestores, convertem-se em indícios de descompromisso com o direito à educação das crianças hospitalizadas. 


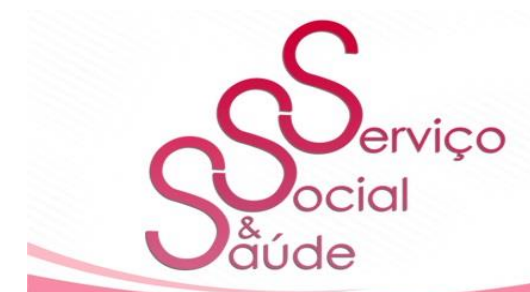

ISSN 2446-5992

(c) (i) (3) (2)

doi: $10.20396 /$ sss.v19i0.8661055

Em relação ao processo de acompanhamento e de gestão das ações educacionais que são desenvolvidas na classe hospitalar, há muito que avançar, pois foi possível obter pelo relato dos professores e coordenadora que as ações nesse sentido se mostram incipientes e frágeis. A ausência de um acompanhamento regular por parte da secretaria estadual de educação, apontada pelos profissionais da classe, denota certo descompromisso com o trabalho desempenhado na classe hospitalar, a despeito do que preconizam os documentos orientadores do MEC.

Segundo disciplina o documento orientador do MEC intitulado, "Classe hospitalar e atendimento pedagógico domiciliar: estratégias e orientações", compete às Secretarias Estaduais e Municipais de Educação, o acompanhamento das classes hospitalares. Tal acompanhamento deve considerar o cumprimento da legislação educacional, a execução da proposta pedagógica, o processo de melhoria da qualidade dos serviços prestados, as ações previstas na proposta pedagógica, a qualidade dos espaços físicos, instalações, os equipamentos e a adequação às suas finalidades, a articulação da educação com a família e a comunidade (BRASIL, 2002).

Os profissionais também ressaltaram a falta de interlocução entre as duas pontas do atendimento que envolve a Área de Educação e da Saúde, o que contraria a Resolução no 2, do Conselho Nacional de Educação, de 11 de setembro de 2001, a qual estabelece que os sistemas de ensino, mediante ação integrada com os sistemas de saúde, devem organizar o atendimento educacional especializado a alunos impossibilitados de frequentar as aulas em razão de tratamento de saúde que implique internação hospitalar, atendimento ambulatorial ou internação prolongada em domicílio.

A classe hospitalar estudada apresenta sua particularidade, mas também guarda semelhanças com outras que não medem esforços para assegurar a educação de crianças e adolescentes em condição de enfermidade e de hospitalização, demandatários temporários da Educação Especial, mesmo diante de uma realidade com tantos desafios. Buscou-se, assim, evidenciar a pertinência e a correlação de tal espaço educacional com o cumprimento das

\begin{tabular}{|l|l|l|l|l|l|}
\hline Serv. Soc. \& Saúde & Campinas, SP & v. 19 & $1-25$ & e020002 & e-ISSN 2446-5992
\end{tabular}




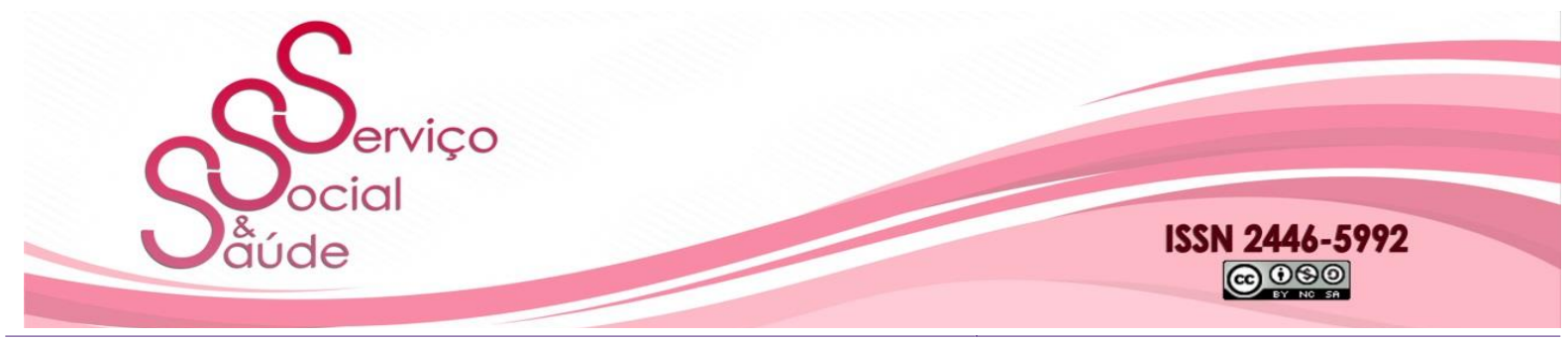

doi: $10.20396 /$ sss.v19i0.8661055

diretrizes legais para seu pleno funcionamento e garantia do direito à educação de crianças e adolescentes hospitalizados.

\section{CONSIDERAÇÕES FINAIS}

Embora exista uma legislação que respalda a educação de crianças e adolescentes hospitalizados, ainda não há uma política bem delineada para tratar das peculiaridades das classes hospitalares, conforme a realidade estudada. Ainda persistem lacunas quanto às formas de atuação do professor, ao vínculo de trabalho dos docentes, bem como inexiste uma formação específica para o trabalho na classe hospitalar, o que na prática implica uma série de indefinições que, inevitavelmente, afetam a dinâmica de ensino-aprendizagem.

O simples fato de instalar classes hospitalares e contratar professores não concretiza a efetivação do direito à educação, porque para isto se exige o cumprimento de condições objetivas de trabalho para os docentes e de qualidade estrutural e pedagógica para os educandos - condições estas que devem estar ancoradas em uma política de gestão que independa de casuísmos.

Falar de educação em hospitais é adentrar em uma seara tênue. Não bastasse a complexidade do próprio ambiente hospitalar e dos sujeitos hospitalizados, crianças e adolescentes em desenvolvimento, existem ainda os desafios enfrentados na seara educacional, conforme pontuado no texto.

Nesse sentido, apesar dos inúmeros desafios enfrentados no cotidiano dos professores da classe, os alunos recebem atendimento educacional, no sentido do acesso oportunizado. Existem, sim, casos em que se alcança o escopo de manutenção da escolaridade, mas não se pode concluir que esta é a regra geral, tendo em vista que há condições essenciais que não são observadas e interferem diretamente na qualidade desses atendimentos. 


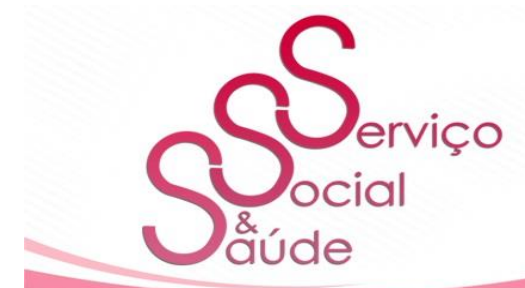

ISSN 2446-5992

(c) (i) (3) (2)

doi: $10.20396 /$ sss.v19i0.8661055

Pensar que o engajamento e a criatividade dos professores da classe analisada, mesmo frente a tantos impasses, significa o retrato das demais classes hospitalares no Brasil, seria um otimismo disfarçado.

A intencionalidade da reflexão, ora realizada, reside em pensar a realidade implícita na condição da efetivação da educação de crianças e adolescentes hospitalizados, no sentido de contribuir para o fortalecimento da estratégia do atendimento educacional hospitalar na modalidade de classe hospitalar - que ainda permanece na invisibilidade para os gestores e até mesmo por grande parcela da sociedade, que desconhece a possibilidade de manutenção do direito à educação da criança e do adolescente em condição de hospitalização.

Assim, as considerações expendidas não constituem uma resposta definitiva à problemática exposta; ao reverso disso, intenciona fomentar possibilidades, debates, (re)construções sobre a educação em âmbito hospitalar, tendo como pano de fundo a legislação pertinente à manutenção ao acesso da criança hospitalizada à escola e o seu direito à Educação.

Recebido em julho de 2020 - Aprovado em julho de 2020.

\section{REFERÊNCIAS}

ALVES, N. Espaço e tempo de ensinar e aprender. In: CANDAU, V. M. (Org.). Linguagens, espaços e tempos no ensinar e aprender. Rio de Janeiro: DP\&A. p. 21-33, 2001. ASSIS, W. de. Classe hospitalar: um olhar pedagógico singular. São Paulo: Ed. Phorte: 2009.

BARDIN, L. Análise de Conteúdo. Tradução: Luís Antero Reta e Augusto Pinheiro. Portugal: Edições 70, 1977. 


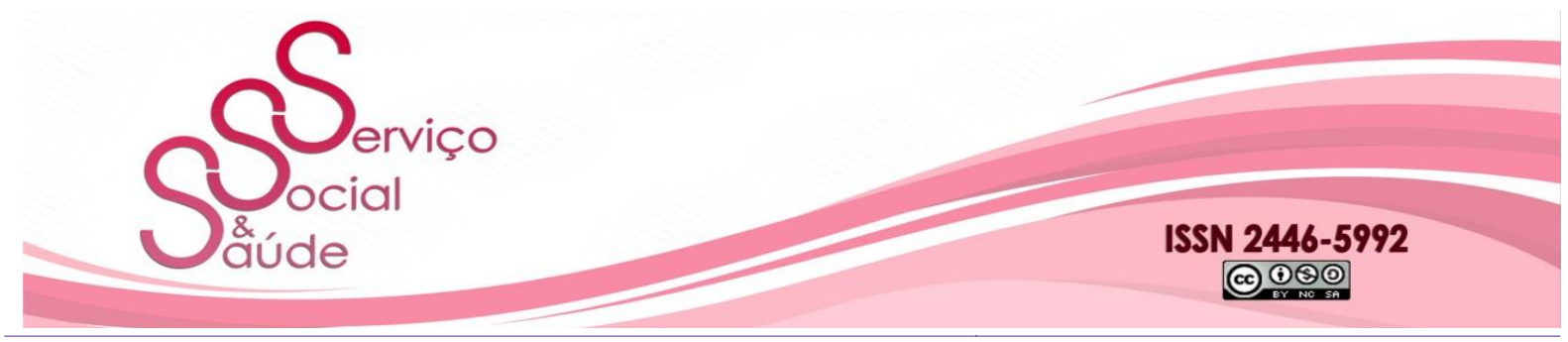

doi: $10.20396 /$ sss.v19i0.8661055

BARROS. A. S. Contribuições da Educação Profissional em Saúde à Formação para o Trabalho em Classes Hospitalares. Caderno CEDES. Campinas, vol. 27, n. 73, p. 249-368, set./dez., 2007.

BEHRENS, M. A. Caminhos da escolarização hospitalar para uma visão de complexidade. In: MATOS, E. L.M. (Org.). Escolarização Hospitalar: Educação e Saúde de mãos dadas para humanizar. Petrópolis, Rio de Janeiro: Editora Vozes, 3. ed., p. 9-20, 2012.

BRANDÃO, C. R. O que é educação. São Paulo: Brasiliense, 1981.

BRASIL. Conselho Nacional de Educação. Resolução n 2, de 11 de setembro de 2001. Institui as Diretrizes Nacionais para a Educação Especial na Educação Básica. Disponível em:<http://portal.mec.gov.br/cne/arquivos/pdf/CEB0201.pdf>. Acesso em: 04 jan. 2020. BRASIL. Conselho Nacional dos Direitos da Criança e do Adolescente. Resolução no 41, de 13 outubro de 1995. Dispõe sobre os Direitos da Criança e do Adolescente Hospitalizados. Disponível em:< https://www.ufrgs.br/bioetica/conanda.htm>. Acesso em: 04 jan. 2020.

BRASIL. Constituição da República Federativa do Brasil de 1988. Disponível em:<http://www.planalto.gov.br/ccivil_03/constituicao/constituicao.htm>. Acesso em: 20 nov. 2019.

BRASIL. Lei no 8.069, de 13 de julho de 1990. Dispõe sobre o Estatuto da Criança e do Adolescente e dá outras providências. Disponível em: < http://www.planalto.gov.br/ccivil_03/leis/18069.htm>. Acesso em: 10 dez. 2019.

BRASIL. Lei no 9.394, de 20 de dezembro de 1996. Estabelece as Diretrizes e Bases da Educação Nacional. Disponível em: 〈http://www.planalto.gov.br/ccivil_03/leis/19394.htm>. Acesso em 15 dez. 2019.

BRASIL. Lei 13.716, de 24 de setembro de 2018. Altera a Lei ${ }^{\circ} 9.394$, de 20 de dezembro de 1996 (Lei de Diretrizes e Bases da Educação Nacional), para assegurar atendimento educacional ao aluno da educação básica internado para tratamento de saúde em regime hospitalar ou domiciliar por tempo prolongado. Disponível em:

https://www2.camara.leg.br/legin/fed/lei/2018/lei-13716-24-setembro-2018-787190publicacaooriginal-156470-pl.html

\begin{tabular}{l|l|l|l|l|l}
\hline Serv. Soc. \& Saúde & Campinas, SP & v. 19 & $1-25$ & e020002 & e-ISSN 2446-5992 \\
\hline
\end{tabular}




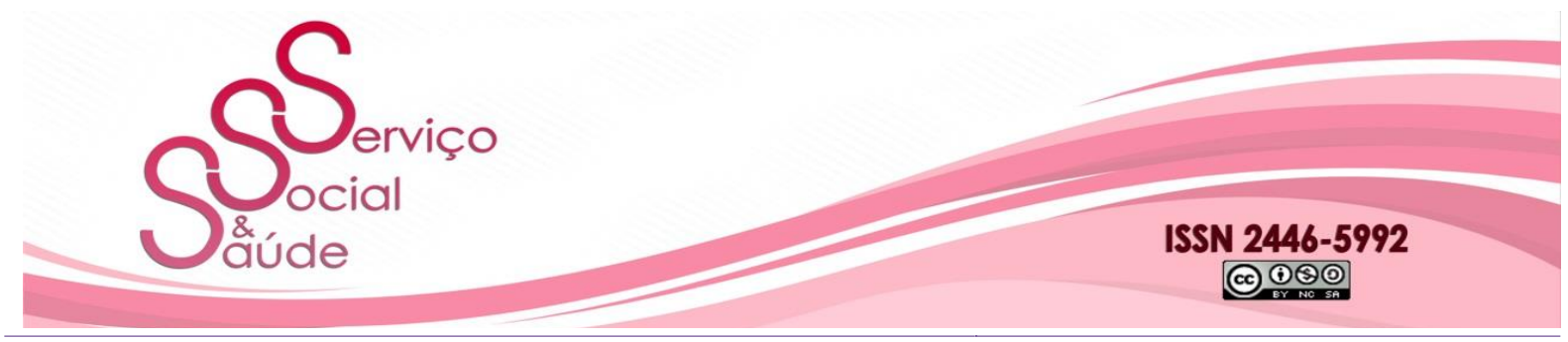

doi: $10.20396 /$ sss.v19i0.8661055

BRASIL. Ministério da Educação. Classe hospitalar e atendimento pedagógico domiciliar: estratégias e orientações. Brasília: MEC, SEESP, 2002. Disponível em: <http://portal.mec.gov.br/seesp/arquivos/pdf/livro9.pdf $>$. Acesso em: 05 dez. 2019. FONSECA, E. S. da. Atendimento escolar no ambiente hospitalar. 2.ed. São Paulo: Memnon, 2008.

BRASIL. Atendimento pedagógico-educacional para crianças e jovens hospitalizados: realidade nacional. Brasília: MEC/INEP, Série Documental: Textos para Discussão, 25 p. 1999.

FONTES, R. O desafio da educação no hospital. Belo Horizonte: Presença pedagógica, v. II, n. 64, p. 21-29, jul./ago. 2005.

FREIRE, P. Pedagogia da autonomia: saberes necessários à prática educativa. São Paulo: Paz e Terra, 1996.

FREIRE, P. Pedagogia do oprimido. Rio de Janeiro: Paz e Terra, 2011.

GONÇALVES, A. G. Escola no Hospital: contribuições do atendimento pedagógicoeducacional para crianças e adolescentes hospitalizados. In: MAZINI, J. E. (Org.). Educação Especial e Inclusão: temas atuais. São Carlos: Marquezine e Manzini, ABPEE, 2013.

ONU. Organização das Nações Unidas. Declaração Universal dos Direitos Humanos da ONU. Disponível em: < https://www.ohchr.org/EN/UDHR/Pages/Language.aspx?LangID=por>. Acesso em: 30 nov. 2019.

ORTIZ, L. C. M.; FREITAS, S. N. Classe Hospitalar: caminhos pedagógicos entre saúde e educação. Santa Maria, RS: UFSM, 2005.

RAMOS, M. A. de M. Classe hospitalar: processos e práticas educativas pela humanização. 2016. Tese (Doutorado em Educação). Universidade Federal Fluminense, Faculdade de Educação, Rio de Janeiro, 2016.

SAVIANI, D. Pedagogia histórico crítica: primeiras aproximações. 8. ed. São Paulo: Ed. Autores Associados, 2003.

SILVA, J. A. da. Curso de Direito Constitucional Positivo. 33. ed. São Paulo: Malheiros Editores, 2009.

\begin{tabular}{l|l|l|l|l|l}
\hline Serv. Soc. \& Saúde & Campinas, SP & v. 19 & $1-25$ & e020002 & e-ISSN 2446-5992 \\
\hline
\end{tabular}


TORRES, W. C. A criança diante da morte: desafios. São Paulo: Casa do Psicólogo, 1999.

VEIGA, I. P. Projeto político-pedagógico da escola de Ensino Médio e suas articulações com as ações da Secretaria de Educação. Anais do I Seminário Nacional: currículo em movimento - perspectivas atuais Belo Horizonte, novembro de 2010.

VYGOTSKY, L. S. A construção do pensamento e da linguagem. São Paulo: Martins Fontes, 2001.

ZARDO, S. P.; FREITAS, S. N. Educação em classes hospitalares: transformando ações e concepções à luz da teoria da complexidade. Educ. rev., Curitiba, n. 30, p. 185-196, 2007. Disponível em:

<http://www.scielo.br/scielo.php?script=sci_arttext\&pid=S010440602007000200012\&lng=en $\&$ nrm=iso>. Acesso em: 01 fev. 2020.

ZOMBINI, et. al. Classe hospitalar: a articulação da saúde e educação como expressão da política de humanização do SUS. Revista Trabalho Educação e Saúde, Rio de Janeiro, v.10, n.1, p.71-86, mar./jun.2012. 